\title{
Modelo Digital de Elevação de Baixo Custo para Unidades de Conservação Marinhas
}

\author{
Low-cost digital elevation model for marine protected areas
}

\author{
Jhone Caetano de Araujo ${ }^{1}$ \\ José Carlos Sícoli Seoane 1 \\ Orlando Nelson Grillo ${ }^{2}$ \\ Elisa Elena de Souza Santos ${ }^{1}$ \\ Fernando Coreixas de Moraes ${ }^{3,4}$
}

Recebido em agosto de 2018.

Aprovado em março de 2019.

\begin{abstract}
RESUMO
Modelos Digitais de Elevação (MDE) são essenciais para a compreensão dos diferentes terrenos, pois representam a adequadamente a geomorfologia original, e através de processamentos, permitem interpretações transdisciplinares de grande valia para a gestão de áreas de preservação. Os mapeamentos topográficos e batimétricos existentes para o Monumento Natural do Arquipélago das Ilhas Cagarras não atendem às necessidades de gestão devido à sua escala, apresentando cotas altimétricas dispersas e pouco detalhe. Por se tratar de uma Unidade de Conservação de proteção integral, ambiente sensível, o mapeamento por sensoriamento remoto é uma ótima ferramenta de levantamento sem interferência direta. O MDE batimétrico foi elaborado a partir do levantamento de campo realizado em barco inflável, numa malha amostral com espaçamento máximo de 50 metros entre linhas, com profundidades obtidas por ecobatímetro comercial acoplado a GPS, corrigidas para a variação de maré, e posterior modelagem da superfície contínua pelo interpolador Topo to Raster. Para o MDE topográfico, foram comparados três levantamentos: SRTM 30 m, ASTER GDEM e por estereofotogrametria, que foram comparados em relação as suas altitudes em 23 pontos de controle, e em suas aparências. O interpolador Topo to Raster gerou um erro médio quadrático submétrico $(0,98 \mathrm{~m})$. O MDE por estereofotogrametria captou melhor as amplitudes altimétricas, a sinuosidade do relevo e se mostrou mais próximo da geomorfologia original. O MDE final, corresponde a fusão do MDE batimétrico com o MDE topográfico estereofotogramétrico, e este trabalho
\end{abstract}

\footnotetext{
${ }^{1}$ Universidade Federal do Rio de Janeiro - UFRJ Instituto de Geociências /Departamento de Geologia Rio de Janeiro/RJ, Brasil. E-mail: jhone@ufrj.br, cainho@geologia.ufrj.br, elisa_elena@ufrj.br ${ }^{2}$ Universidade Federal do Rio de Janeiro - UFRJ Museu Nacional / Departamento de Geologia e Paleontologia/ Laboratório de Processamento de Imagem Digital Rio de Janeiro/RJ, Brasil E-mail: ongrillo@mn.ufrj.br

${ }^{3}$ Instituto de Pesquisas Jardim Botânico do Rio de Janeiro Diretoria de Pesquisas, Rio de Janeiro/RJ, Brasil

${ }^{4}$ Museu Nacional - UFRJ Seção de Assistência ao Ensino, Rio de Janeiro/RJ, Brasil. E-mail: fmoraes@mn.ufrj.br
} 
apresenta uma metodologia de baixo custo e de ampla aplicação para geração de MDE em áreas marinhas protegidas.

PALAVRAS-CHAVE: Modelo Digital de Elevação, Batimetria, Estereofotogrametria, Levantamento de Baixo Custo.

\begin{abstract}
Digital Elevation Models (DEM) are essential for a better comprehension of different terrains, as they represent the original geomorphology, and through processing, such as color classification of data, shaded relief, slope, direction of faces and curvature, allows for a range of transdisciplinary interpretations of great value to the management of conservation areas. Mona Cagarras is the chosen spatial area and has positive and negative altimetry amplitudes. For such a fully protected Conservation Unit (CU), remote sensing mapping is an adequate tool for data acquisition, causing no direct interference to the sensitive environment. Existing topographic and bathymetric data do not attend management's needs for precision, as the altimetric data are scattered and little detailed. The bathymetric DEM was produced from a field survey, using a commercial echo sounder attached to a GPS, with the modeling of the continuous surface done by the Topo to Raster interpolator. For the topographic DEM, three methodologies have been tested: SRTM 30m, ASTER GDEM and survey-based stereophotogrammetry. The resulting DEMs were compared to 23 ground control points and analyzed for their appearance. The stereophotogrammetry best caught the altimetric amplitudes and the winding relief, and proved to be more similar to the original geomorphology. The final DEM corresponds to the sum of the bathymetric DEM and stereophotogrammetrical topographic DEM. The interpolator Topo to Raster generated a submetrical RMS of $0.98 \mathrm{~m}$. The large range of bathymetric detail is of huge importance in marine protected areas, as they are the basis to the knowledge of ecosystems. This paper presents a low cost methodology and has potential to become widely applied to aid management in marine protected areas.
\end{abstract}

KEYWORDS: Digital Elevation Model, Bathymetry, Stereophotogrametry, Low-Cost Survey

$$
* * *
$$

\title{
Introdução
}

Os Modelos Digitais de Elevação - MDE- tem se difundido como superfície base para estudos em diversas áreas da ciência e em grande parte para análises ambientais. Os MDEs simulam o relevo e as cotas altimétricas, e podem ser obtidos por processos fotogramétricos, cartas topográficas e sensores variados (FERNANDES et al, 2012). Um MDE pode ser representado vetorialmente, com curvas de nível por exemplo, ou 
matricialmente, através de um sistema de coordenadas espaciais (X e Y) e elevação (Z) (FUCKNER et al, 2009).

Apesar de sua grande importância estratégica, não é ainda possível encontrar um mapeamento sistemático de grande escala para todo o território nacional. A base contínua nacional em escala de 1:1.000.000 e cartas topográficas de variadas escalas, recobrindo áreas descontínuas, do Instituto Brasileiro de Geografia e Estatística - IBGE e da Diretoria do Serviço Geográfico - DSG, se configuram na melhor base de dados nacional, embora possuindo pouco detalhe em função da escala e sistematização.

Com vistas ao conhecimento cartográfico mais aprofundado, para melhor planejamento e gestão do território, buscam-se atualizações constantes e em diversas escalas. Dentro deste contexto, o Sensoriamento Remoto - SR - é não somente uma ciência, como uma arte imprescindível de aquisição de dados, inclusive em escala global, sem estar em contato físico direto com o objeto alvo (JENSEN, 2009).

Os sensores remotos detectam a energia eletromagnética através das variações da radiação eletromagnética (REM) emitida ou refletida pelo alvo. As informações coletadas são geradas por sistemas sensores imageadores ou não-imageadores, tendo como produto imagens ou dígitos, respectivamente. Os sistemas sensores que não possuem fonte própria de energia eletromagnética, como câmera fotográfica, radiômetros e espectroradiômetros, são chamados de passivos e os sensores que emitem a energia eletromagnética, como Radio Detection and Ranging - RADAR, de ativos (MORAES, 2002). Os sensores remotos são ainda classificados em: terrestres, aéreos e orbitais levando-se em consideração o local da plataforma que abriga ou transporta o sensor (FLORENZANO, 2007).

A modelagem do relevo pelas técnicas de SR são ainda mais relevantes no âmbito das atividades em Unidade de Conservação - UC, pois não há interferência direta do levantamento topográfico tradicional com mobilização de equipe em ecossistema sensível e sob algum nível de proteção. 
Este trabalho tem por objetivo a apresentação de metodologia de baixo custo, ou seja, por uma fração do custo de um levantamento comercial (ARAUJO et al, 2015, HATANAKA et al, 2007, HEYMAN et al, 2007) e de ampla aplicação na construção de MDE em áreas marinhas protegidas, e da costa brasileira como um todo, utilizando técnicas de SR. Esta metodologia fornece um modelo confiável da base física para atividades que necessitem de alta precisão batimétrica (resoluções espaciais abaixo de $10 \mathrm{~m}$ ) e precisão topográfica suficiente para atividades de campo e reconhecimento de macro feições geomorfológicas.

\section{Referencial teórico}

Os primeiros estudos de MDE foram construídos a partir das curvas de nível e cotas de topos altimétricos das cartas topográficas elaboradas pelas Divisões de Diretoria do Serviço Geográfico do Exército - DSG - e pelo IBGE. Nessa metodologia, as cartas são digitalizadas, georreferenciadas, ortorretificadas, as curvas de nível e topos cotados vetorizados e os modelos contínuos da superfície gerados. Esta, ainda é uma das formas de se fazer MDE, porém a aquisição de dados em campo é lenta e o custo é elevado (MELGAÇO et al, 2005).

Na década de 1980 a fotogrametria digital surgiu como ramo mais recente da ciência fotogramétrica. A metodologia consiste na utilização de imagens digitais espacialmente sequenciais e com áreas com superposição, obtidas por câmara digital ou digitalização matricial de imagens analógicas, para se obter visão estereoscópica. Contudo, foi a partir da década de 1990 que a metodologia pôde ser aplicada de maneira ampla, em razão do aumento da capacidade de processamento dos computadores (COELHO FILHO e BRITO, 2007). Entre as aplicações fotogramétricas destacam-se a produção de cartas topográficas; MDE; projeto, locação e manutenção de estradas; inventário florestais e minerais; cadastro e planejamento urbano em escala de mapeamento cadastral; todas de grande importância nas geociências 
(TOMMASELLI, 2009). No contexto das novas geotecnologias, a estereofotogrametria se apresenta como uma excelente ferramenta de aquisição e apresentação de dados em ambiente de SIG e de realidade virtual - RV.

O avanço constante da tecnologia espacial impulsionou o lançamento de uma série de satélites para coleta de dados variados, com pioneirismo para o satélite metereológico Television IR Operational Satellite - TIROS-1. Pela primeira vez foram observadas feições da superfície da Terra e padrões de cobertura de nuvens. Considerado como um marco inicial importante para o sensoriamento remoto, o satélite Landsat 1 foi colocado em órbita em 1972 fornecendo quatro imagens nas faixas do visível e infravermelho próximo e uma na termal e resolução espacial de $80 \mathrm{~m}$ (BIAS et al, 2012). O projeto Landsat está operando até os dias atuais e lançou oito satélites em sua história de mais de 40 anos se configurando em uma excelente ferramenta de análise espacial regional.

Os dados altimétricos capturados por sensores podem ser obtidos por estereoscopia (superposição de fotografias/imagens) ou interferometria (superposição de ondas e energia). Com objetivo de mapear o relevo global a Shuttle Radar Topographic Mission - SRTM e o Global Digital Elevation Map gerado pelo sensor Advanced Spaceborne Thermal Emission and Reflection Radiometer a bordo do satélite Terra - GDEM/ASTER/Terra, se configuram nos principais produtos de MDE de origem orbital de ampla aquisição e disponibilidade sem custos.

Em fevereiro de 2000 foi realizado o experimento do SRTM. A missão teve realização da National Aeronautics and Space Administration - NASA e da National Geospatial - Intelligence Agency - NGA - com colaboração da Agenzia Spaziale Italiana - ASI - e da Deutsches Zentrumfür Luft- und Raumfahrt - DLR. Os dados altimétricos foram extraídos utilizando técnica de interferometria, a partir de uma dupla de sensores de abertura sintética distantes $60 \mathrm{~m}$ entre si e transportados pelo Ônibus Espacial Endeavour (MELGAÇO et al, 2005). Os modelos altimétricos SRTM possuem resolução 
espacial de $30 \mathrm{~m}$, entretanto até a década passada, para a América do Sul, a NASA disponibilizava o produto com $90 \mathrm{~m}$ de resolução que pode ser adquirido gratuitamente em formato GeoTiff de 16 bits, coordenadas geográficas, sistema de referência WGS-84 e altitude em metros através do endereço eletrônico: http://www.relevobr.cnpm.embrapa.br/download/ da Empresa Brasileira de Pesquisa Agropecuária - EMBRAPA (TOMAZONI et al, 2011; MIRANDA, 2005). Com o intuito de aprimorar a resolução dos dados SRTM para o Brasil, o Instituto Nacional de Pesquisas Espaciais - INPE - desenvolve desde 2008 o projeto Topodata que processa e disponibiliza o dados SRTM reamostrados com resolução espacial de $30 \mathrm{~m}$, igual a disponibilizada nos Estados Unidos (VALERIANO e ROSSETI, 2010). O MDE processado pode ser baixado gratuitamente no endereço eletrônico: http://www.webmapit.com.br/inpe/topodata/. No início desta década, o United States Geological Survey - USGS - lançou e vem aprimorando a ferramenta EarthExplorer com o intuito de facilitar o download de geoinformação para o público em geral. Através do endereço eletrônico: https://earthexplorer.usgs.gov/ é possível baixar cenas da missão SRTM com resolução de $30 \mathrm{~m}$, inclusive da América do Sul. Os dados SRTM vem sendo aferidos por vários autores, sendo considerados adequados para produzir bases cartográficas confiáveis até o detalhe de 1:50.000 (BIAS et al, 2011, MICELI et al, 2011).

Em julho de 2009 foi publicada a segunda versão do GDEM/ASTER com base em produto de estereoscopia (FUCKNER et al, 2009). O instrumento ASTER foi desenvolvido pela Ministry of Economy, Trade and Industry METI - do Japão e a NASA possuindo a capacidade de estereoscopia ao longo da trajetória utilizando pares de imagens adquiridos pelo subsistema VNIR com uma banda 3N (nadir) e 3B (backwardlooking) em ângulo de retrovisada aproximado de 27 graus. (TACHIKAWA et al, 2011; FUCKNER et al, 2009; ABRAMS e HOOK, 2002). Esse produto é superior aos sensores que utilizam pares de imagens adquiridos em órbitas diferentes devido ao pequeno intervalo de tempo de obtenção, dessa forma diminuindo as diferenças 
radiométricas, as condições de iluminação da cena e a cobertura de nuvens entre as duas imagens da composição. O ASTER permite a construção de MDEs nas resoluções de $30 \mathrm{~m}$ e $15 \mathrm{~m}$, embora não tenham sido notadas, em comparação, grandes diferenças de elevação (MELGAÇO et al, 2005).

De maneira geral, a tecnologia aplicada nos sensores em concordância, com a plataforma utilizada revela as diversas escalas de aquisição de dados. Em pequenas escalas, os sistemas sensores orbitais como SRTM e GDEM ASTER abrangem quase que toda a superfície do planeta com resolução espacial de $90 \mathrm{~m}$ ou $30 \mathrm{~m}$. Em médias escalas são aplicadas técnicas de interferometria por radar, para médias e altas resoluções espaciais. Para grandes escalas e uso local, destacam-se as técnicas com as maiores resoluções espaciais que estão pautadas atualmente em aerofotogrametria e laser de varredura do tipo Light Detection and Ranging - LIDAR - aerotransportado (TIGHE E CHAMBERLAIN, 2009).

Os dados topográficos são bem mais difundidos e de boa qualidade em relação aos dados batimétricos, principalmente em áreas costeiras (PICKRILL e TODD, 2003). Os sensores orbitais gratuitos coletam dados em pequenas profundidades (KRUG e NOERNBERG, 2005). Sistemas sensores do tipo LIDAR adquirem dados em até $70 \mathrm{~m}$ de coluna d'água, porém com custo elevado (GAO, 2009). Os sensores do tipo Sound Navigation and Ranging - SONAR - são os mais difundidos para aquisições batimétricas e os sonares de varredura lateral - sidescan sonar - geram imagens através da refletividade do fundo sendo possível observar características morfológicas e texturais (CWIK et al, 2010). Para grandes áreas e profundidades que vão do nível do mar até mais de $1 \mathrm{~km}$, são encontrados os tradicionais trabalhos de ecobatimetria, ou seja, detecção do assoalho oceânico a partir de sensores acústicos (HEEZEN, et al, 1959; POULIQUEN e LURTON, 1992 ). Com mapeamentos utilizando tecnologia monofeixe (SÁNCHEZ-CARNERO et al, 2012; HORTA et al, 2014; KVERNEVIK et al, 2002) ou multifeixe (VILMING, 1998; BIJU-DUVAL et al, 1982). 
A ecobatimetria baseia-se em sensores ativos que calculam a profundidade pelo intervalo de tempo entre a onda acústica emitida e recebida, tendo em vista ser conhecida a propagação do som na água. A utilização de um único sensor, chamado transdutor, o caracteriza como sendo monofeixe e de aquisição restrita ao local abaixo ao trajeto da embarcação, enquanto vários transdutores constituem uma composição multi feixe, e coletam informações em uma faixa maior (CWIK et al, 2010). Outras formas de se obter um modelo batimétrico são por exemplo, a partir da digitalização de cartas náuticas e/ou folhas de bordo da Marinha (DIAS et al, 2014), que dependem da disponibilidade de carta com escala compatível com o trabalho.

Os sensores monofeixe possuem uma série de vantagens em relação aos multifeixes pois não possuem elevado custo de aquisição. Também são justificáveis em áreas rasas onde a eficiência do multifeixe é reduzida. Não necessitam de atenção a calibração constante de todos os sensores, e permitem processamentos mais rápidos devido ao número menor de dados. Exigem menos recursos computacionais e podem atingir grande precisão com o aumento da grade amostral, não sendo necessárias grandes adaptações nas embarcações (VICENTE et al, 2005).

Devido ao aumento da disponibilidade dados de sensores, gratuitos ou de baixo custo, associados à incessante melhoria em equipamentos e técnicas de SR, antes muito dispendiosas, novas perspectivas de planejamento e gestão ambiental são potencializadas. As principais características dos métodos de levantamento topográfico e batimétrico são resumidos na Tabela 1. 
Tabela 1 - Comparação entre vários sistemas sensores para aquisição de dados topográficos e batimétricos

\begin{tabular}{|c|c|c|c|c|c|}
\hline Sistema & Descrição & Resolução & Virtude & Limitações & Uso em MDE \\
\hline SRTM & $\begin{array}{c}\text { RADAR } \\
\text { interferométrico } \\
\text { orbital }\end{array}$ & $30 \mathrm{~m}$ & $\begin{array}{c}\text { Aquisição em } \\
\text { condições climáticas } \\
\text { adversas e sem fonte } \\
\text { de energia natural. } \\
\text { Gratuito. }\end{array}$ & $\begin{array}{l}\text { Não apresenta bons } \\
\text { resultados em } \\
\text { pequenas escalas e } \\
\text { diferenças } \\
\text { altimétricas } \\
\text { abruptas. }\end{array}$ & $\begin{array}{c}\text { Modelo } \\
\text { topográfico de } \\
\text { pequena escala }\end{array}$ \\
\hline ASTER & $\begin{array}{c}\text { Estereoscopia } \\
\text { por par de } \\
\text { imagens do } \\
\text { subsistema } \\
\text { VNIR } \\
\end{array}$ & $30 \mathrm{~m}$ & $\begin{array}{l}\text { Pequeno intervalo de } \\
\text { tempo na aquisição do } \\
\text { par de imagens. } \\
\text { Gratuito. }\end{array}$ & $\begin{array}{l}\text { Condições do clima e } \\
\text { pequenas escalas. }\end{array}$ & $\begin{array}{c}\text { Modelo } \\
\text { topográfico de } \\
\text { pequena escala }\end{array}$ \\
\hline Estereofotogrametria & $\begin{array}{c}\text { Fotografias } \\
\text { sobrepostas com } \\
\text { câmara } \\
\text { fotográfica }\end{array}$ & $\mathrm{cm}$ & $\begin{array}{l}\text { Modelos precisos e } \\
\text { materiais de alto, } \\
\text { médio e baixo custo. }\end{array}$ & $\begin{array}{c}\text { Condições do clima e } \\
\text { conhecimento } \\
\text { específico }\end{array}$ & $\begin{array}{c}\text { Modelo } \\
\text { topográfico de } \\
\text { pequena e média } \\
\text { escala }\end{array}$ \\
\hline LIDAR & Laser & $\mathrm{mm}$ & $\begin{array}{l}\text { Nuvens de ponto com } \\
\text { grande precisão. }\end{array}$ & $\begin{array}{c}\text { Vento, material de } \\
\text { superfície, } \\
\text { geomorfologia e } \\
\text { conhecimento } \\
\text { específico. Alto custo. }\end{array}$ & $\begin{array}{c}\text { Modelo } \\
\text { topográfico e } \\
\text { batimétrico de } \\
\text { pequena e média } \\
\text { escala }\end{array}$ \\
\hline $\begin{array}{c}\text { Ecobatimetria Mono } \\
\text { Feixe }\end{array}$ & $\begin{array}{c}\text { Sonda acústica } \\
\text { de registro } \\
\text { único }\end{array}$ & $\mathrm{m}$ até $\mathrm{cm}$ & $\begin{array}{c}\text { Menor custo e tempo } \\
\text { de processamento. } \\
\text { Pequenas } \\
\text { profundidades e } \\
\text { navegabilidade } \\
\text { favorável em zonas } \\
\text { com muitos } \\
\text { obstáculos. } \\
\end{array}$ & $\begin{array}{l}\text { Condições de mar, } \\
\text { vento e grandes } \\
\text { profundidades. }\end{array}$ & $\begin{array}{c}\text { Modelo } \\
\text { batimétrico de } \\
\text { pequena e média } \\
\text { escala }\end{array}$ \\
\hline $\begin{array}{c}\text { Ecobatimetria Multi } \\
\text { Feixe }\end{array}$ & $\begin{array}{l}\text { Sonda acústica } \\
\text { de múltiplos } \\
\text { registros }\end{array}$ & $\mathrm{cm}$ até $\mathrm{mm}$ & $\begin{array}{c}\text { Ótima precisão e } \\
\text { grande abrangência } \\
\text { espacial. }\end{array}$ & $\begin{array}{l}\text { Condições de mar, } \\
\text { vento e tráfego em } \\
\text { ambientes costeiros. } \\
\text { Profissional com } \\
\text { conhecimento } \\
\text { específico. Alto custo. }\end{array}$ & $\begin{array}{c}\text { Modelo } \\
\text { batimétrico de } \\
\text { pequena e média } \\
\text { escala }\end{array}$ \\
\hline SideScan SONAR & $\begin{array}{c}\text { Sonda acústica } \\
\text { de varredura } \\
\text { lateral }\end{array}$ & $\mathrm{cm}$ até $\mathrm{mm}$ & $\begin{array}{c}\text { Diferenciação da } \\
\text { geomorfologia e } \\
\text { sedimentologia do } \\
\text { assoalho marinho. }\end{array}$ & $\begin{array}{l}\text { Condições de mar e } \\
\text { vento. Custo médio. }\end{array}$ & $\begin{array}{c}\text { Modelo } \\
\text { batimétrico de } \\
\text { pequena e média } \\
\text { escala }\end{array}$ \\
\hline
\end{tabular}

Fonte: Elaborada pelos autores. 


\section{Materiais e métodos}

A área de estudo, os métodos e materiais empregados nas diversas etapas do trabalho são descritos a seguir.

2.1Área de estudo

O Monumento Natural do Arquipélago das Ilhas Cagarras (MoNa Cagarras) é Unidade de Conservação de proteção integral com vistas à preservação da beleza cênica e da importância como área de nidificação. Ao todo, a UC, criada pela Lei $\mathrm{N}^{\circ} 12.229$ em 2010, é formada por seis ilhas que situam-se entre 4 e $9 \mathrm{~km}$ ao sul da Praia de Ipanema e mais a área marinha de $10 \mathrm{~m}$ de entorno de cada ilha (Figura 1).

Figura 1 - Área de estudo: A) Brasil; B) Rio de Janeiro; C) Baía de Guanabara, com destaque para o Arquipélago das Cagarras; D) MoNa Cagarras.

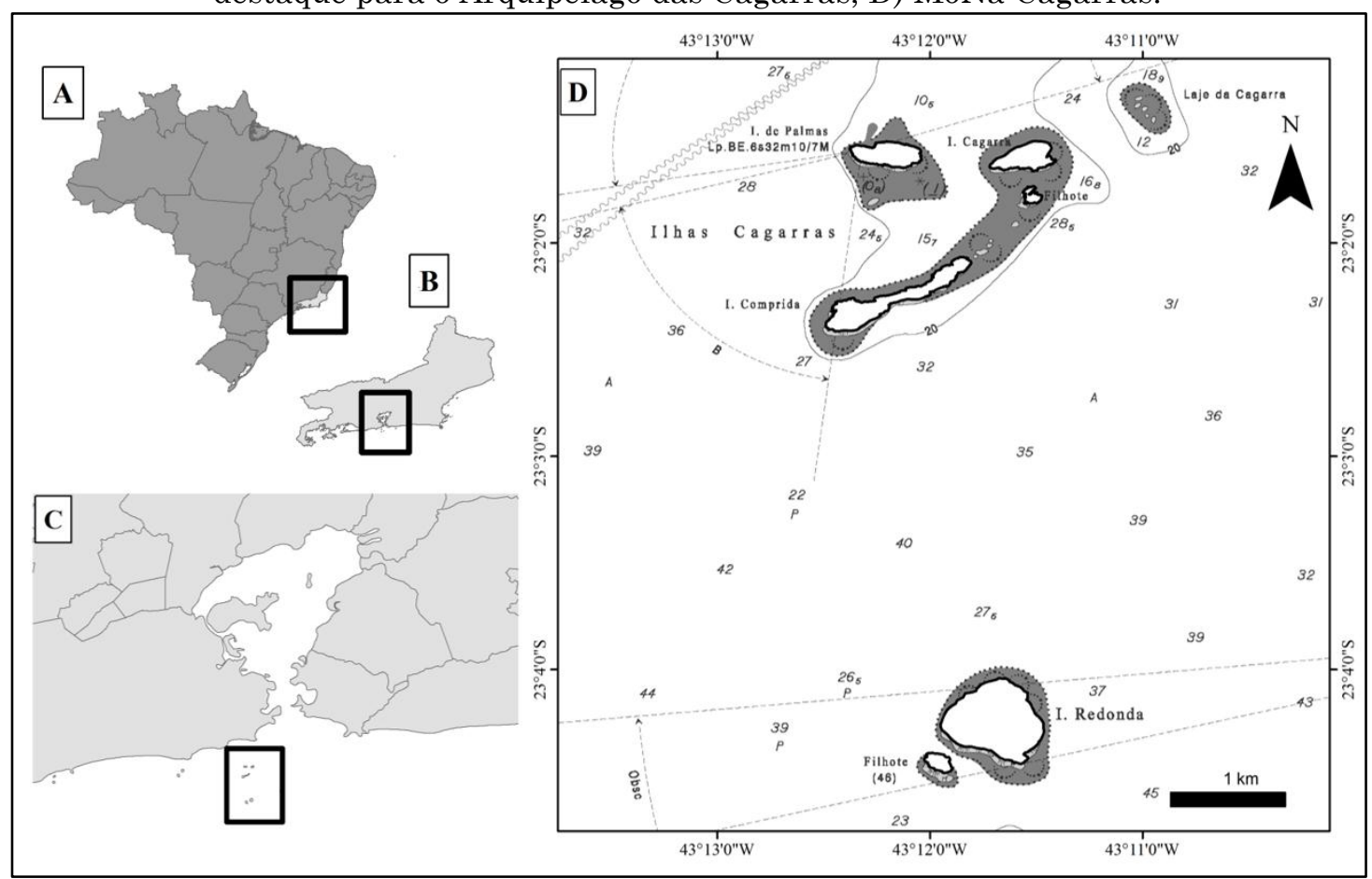

Fonte: IBGE e folha 1501 Baía de Guanabara (DHN, 2017). 


\subsection{Metodologia}

A seguir são descritas as atividades e etapas percorridas para a elaboração do MDE. Em se tratando de UC marinha, o MDE é uma soma das modelagens emersa e submersa. Para tal, técnicas específicas de levantamento de dados foram aplicadas em cada ambiente. Dessa forma, foram dedicados dois subcapítulos com as modelagens batimétrica e topográfica e um subcapítulo final com o MDE propriamente dito.

\subsubsection{Modelagem batimétrica}

O levantamento batimétrico é apresentado nos itens seguintes onde estão dispostos os equipamentos utilizados, o plano da malha amostral, o trabalho de campo e a rotina de processamento no pós-campo.

\subsubsection{Equipamentos}

Para a execução do levantamento batimétrico foram utilizados os seguintes equipamentos: barco, GPS/GNSS sem uma base de referência para posicionamento cinemático em tempo real e ecobatímetro mono feixe. $\mathrm{O}$ barco foi um monomotor inflável de $150 \mathrm{HP}$ da marca ZEFIR® com $7 \mathrm{~m}$. Esse tipo de embarcação facilita a varredura em áreas de baixas profundidades e próximas ao costão rochoso, feições geomorfológicas típicas da área de levantamento, além de transportar o GPS e o ecobatímetro. O equipamento de navegação da embarcação, GPSMAP 521S da marca GARMIN®, possui GPS não diferencial e transdutor acoplado que de maneira conjunta fazem a leitura da posição e profundidade em coordenadas xyz.

Foram utilizados os softwares de geoprocessamento ArcGIS® v.10.2.2 nas suítes ArcMap e ArcScene, com auxílio do GlobalMapper®v.13 e o HomePort ${ }^{\circ}$, da Garmin, para as transformações necessárias a comunicação entre a origem do dado e os ambientes de processamento e modelagem. 


\subsubsection{Planejamento de campo}

O levantamento batimétrico foi planejado dentro de um perímetro de $200 \mathrm{~m}$ entorno de cada uma das ilhas que compõem o MoNa Cagarras. Ao redor das ilhas foram estabelecidas linhas radiais com no máximo $50 \mathrm{~m}$ de espaçamento. Os parâmetros foram definidos em conformidade aos parâmetros de espaçamento para classe 1B do International Hydrographic Organization - IHO (IHO, 2002, 2008). Para que não houvesse lacunas entre as ilhas Comprida, Palmas e Cagarras, foram amostrados pontos em grade regular com espaçamento de 100 e 200 m (Figura 2). Para leitura dos trajetos pelo GPS da embarcação, estes foram criados no formato shapefile (.shp) no software ArcGIS e transformado em .gpx no software GlobalMapper para por fim, ser lido pelo software HomePort e transferido para o cartão SD com extensão .adm.

Figura 2 - Trajetos planejados para execução do levantamento batimétrico sobre imagem GeoEye. O espaçamento máximo planejado entre linhas é de $50 \mathrm{~m}$, conforme recomendação da IHO (2008).
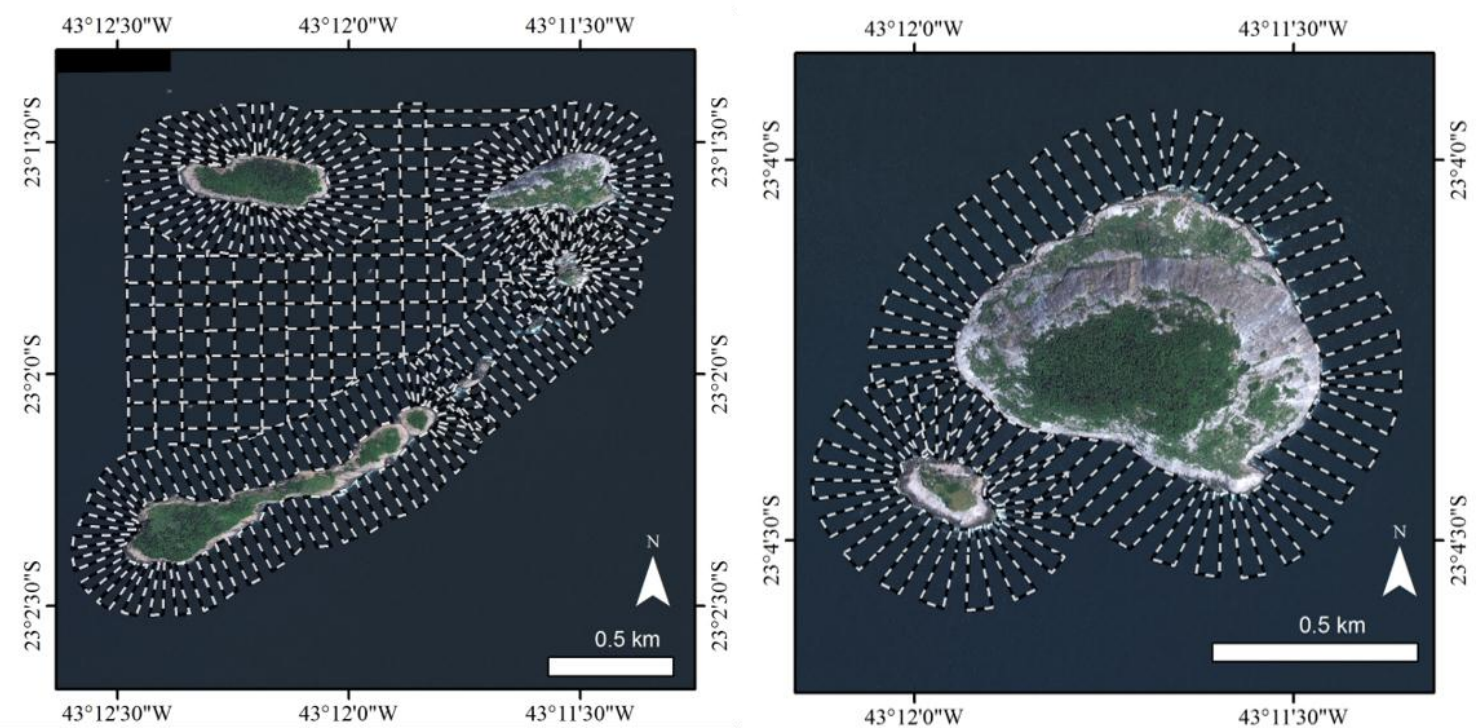

Fonte: Elaborada pelos autores.

Com os trajetos confeccionados, agendou-se as saídas de campo de acordo com condições oceanográficas e climatológicas de calmaria em períodos intramaré na preamar, consultados na tábua de marés da Marinha do Brasil. 


\subsubsection{Trabalho de campo}

O trabalho de campo iniciava-se com o embarque na Colônia de Pescadores Z-13, próximo ao Forte de Copacabana. Os trajetos elaborados em gabinete eram transferidos para o GPS e adicionados à tela de exibição via cartão SD.

O GPS foi configurado para coletar os dados de profundidade em metros, sob sistema de referências cartográficas em Datum WGS84 e em projeção UTM fuso 23S. A projeção UTM facilita os cálculos métricos dos parâmetros da modelagem batimétrica. O intervalo de coleta entre dois pontos em sequência foi de $10 \mathrm{~m}$ e o ecobatímetro colocado em frequência de $50 \mathrm{~Hz}$, que é ideal para baixas profundidades (menores do que $30 \mathrm{~m}$ ).

Após translado de aproximadamente 10 minutos até as Ilhas Cagarras e 20 minutos até a Ilha Redonda, iniciava-se a gravação do percurso e profundidades com atenção aos trajetos exibidos na tela do GPS. O barco mantinha baixa velocidade, com no máximo $7 \mathrm{~km} / \mathrm{h}$ para que o ruído do motor não causasse nenhuma interferência na leitura do transdutor. Com a conclusão do percurso, os dados eram gravados e transferidos para o cartão SD e iniciava o translado de volta à colônia de pescadores.

\subsubsection{Processamento de dados}

Após o trabalho de campo os dados batimétricos adm, salvos no cartão $\mathrm{SD}$, foram abertos no HomePort e transformados em .gpx que lido pelo GlobalMapper foi exportado em extensão .shp para inserção no ArcGIS.

Os arquivos vetoriais .shp possuem graficamente os pontos de coleta dispostos no Data View e na tabela associada, uma série de campos com destaque para as colunas com os registros StartTime - com a data e horário do início da gravação, ElapsedTime - com o tempo total de gravação, Length com a distância total percorrida em $\mathrm{km}$, Position - com as coordenadas 
geográficas dos pontos, Time - com a data e horário da leitura da profundidade e Depth - com a medida da profundidade em metros.

A tabela bruta foi modificada a fim de tornar compatível o formato dos dados para clareza, organização e compatibilidade com as ferramentas de geoprocessamento. O campo Depth estava caracterizado como sendo do tipo texto e com o número que representa a profundidade junto à letra "m", indicativa da unidade de medida em metros. Então criou-se o campo Prof do tipo double, alimentado apenas com os valores numéricos, multiplicados por 1 para se tornarem negativos, ou seja, abaixo da superfície do mar.

Foram eliminados os valores discordantes com o contexto de leitura, isto é, radicalmente diferentes de seus vizinhos mais próximos, por inspeção visual. Esses valores são normalmente gerados a partir da interferência sonora do ruído do motor e em alguns casos a passagem de um cardume, em ambos os casos a leitura é prejudicada, ora pela sobreposição de ondas sonoras, ora pela capacidade refletiva do cardume a ponto de ser interpretado como sendo a profundidade.

Após o processamento individual de cada uma das campanhas de campo, o conjunto de dados batimétrico foram unidos com a ferramenta Merge em dois grupos. Um englobando as Ilhas Cagarras e sua filhote, Palmas, Comprida além das lages Mathias e Praça Onze, e outro com a Ilha Redonda e filhote.

\subsubsection{Interpolação da malha amostral}

A modelagem consiste na inferência de valores contínuos a partir de uma malha amostral pontual e foi executada utilizando a ferramenta Topo to Raster no módulo Interpolation do Arctoolbox do ArcGIS.

O Topo to Raster é um método de interpolação baseado no programa ANUDEM (Australian National University Digital Elevation Model), desenvolvido por HUTCHINSON $(1988,1989)$. Este método impõe restrições, que podem ser estruturas, pontos, linhas, polígonos, bordas e máscaras para 
garantir um modelo de elevação hidrologicamente consistente. Reproduz topos e vales com a superfície passando exatamente pelos pontos amostrados.

Primeiramente foram vetorizados os polígonos com as áreas que serão interpoladas. Os polígonos consistem no contorno dos pontos amostrados, contendo a totalidade dos mesmos com uma pequena margem de distância com o objetivo de não se extrapolar indevidamente a representação matricial. Estes polígonos limitadores são conhecidos como "máscaras" de interpolação.

À ferramenta foi adicionado o shapefile com os dados do levantamento batimétrico, onde na opção Field, local de escolha da coluna cujos valores serão interpolados, foi escolhido o campo Depth, que possui os valores de profundidade e em Type, local de escolha do tipo de dado, o campo Point Elevation, que é o indicado para dados de cotas pontuais.

Em Output cellsize, foi definida a resolução espacial de $10 \mathrm{~m}$, em Drainage enforcement optou-se por NO_ENFORCE a fim de não preencher as depressões, em Primary type of input data a opção SPOT é a que corresponde ao predomínio de dados pontuais, a componente Roughness penalty foi preenchida com o valor de 0,5 por sugestão da ferramenta para dados discretos.

Como último parâmetro, adicionou-se o polígono com a área de interpolação em Mask, na aba Raster analysis do Enviromental settings. Foram mantidas as opções de default para todos os outros parâmetros não citados.

\subsubsection{Modelagem topográfica}

A modelagem topográfica consistiu na obtenção dos modelos SRTM 30m, ASTER GDEM e elaboração de modelos estereofotogramétricos a partir de fotografias feitas em campo. 


\subsubsection{Obtenção dos modelos orbitais}

Os modelos SRTM de $30 \mathrm{~m}$ e o ASTER GDEM foram baixados gratuitamente utilizando a ferramenta Earth Explorer da USGS no endereço eletrônico: http://earthexplorer.usgs.gov/. Ambos possuem formato GeoTIFF, com coordenadas geográficas de latitude e longitude e resolução de um arcosegundo ( 30 m no Equador). Eles são referenciados para o Datum WGS84 / EGM96.A área do MoNa Cagarras foi extraída da cena bruta de cada um dos MDE, com o objetivo de diminuição do volume de processamento de dados. Para tal, ambos MDE foram adicionados ao ArcMap e posicionados de forma que apenas a UC fosse abrangida no Dataview. Os MDE foram recortados utilizando a função Export Raster Data com a opção Data Frame (Current) selecionada no campo Extent que define a área do Dataview como a máscara de recorte.

Ambos os MDE obtidos por SR foram reamostrados para células de 10 m utilizando o algoritmo convolução bicúbica.

\subsubsection{Modelo estereofotogramétrico}

A topografia das ilhas foi reconstruída em 3D usando a técnica de estereofotogrametria que corresponde à derivação precisa de informações tridimensionais de pontos, linhas e áreas do terreno a partir de sequências de fotografias convencionais (MALLISON E WINGS, 2014). Para gerar os modelos 3D, foram usadas 800 fotografias obtidas no nível do mar usando a câmera digital Canon EOS 7D equipada com lente Canon EFS 18-135 mm. Para tanto, o barco contornou cada ilha a uma distância suficiente para permitir o enquadramento completo da ilha usando uma distância focal de 35 a $50 \mathrm{~mm}$. Durante o trajeto, imagens adicionais de detalhes (distância focal de 100 a $135 \mathrm{~mm}$ ) foram também obtidas. O registro foi realizado no início da manhã de um dia ensolarado, para garantir iluminação uniforme e livre de sombras de nuvens. Vistas aéreas foram obtidas a partir de 1.300 quadros 
extraídos de filmagens de alta definição (Full HD), geradas a partir de 1 hora de sobrevoo de helicóptero nas ilhas, utilizando-se câmera acoplada e estabilizada na proa da aeronave. Estas imagens foram obtidas ao longo da produção do documentário Ilhas do Rio: Monumento Carioca (Direção: Fernando Moraes e Mauricio Salles) e disponibilizadas gratuitamente para a elaboração do modelo 3D.

As imagens foram processadas usando o software AgisoftPhotoscan ${ }^{\circledR}$. Cada ilha foi processada individualmente, exceto a Redonda e Filhote que foram processadas em conjunto. As etapas do processo são as seguintes (para detalhes sobre a metodologia, ver Mallison e Wings, 2014): 1) separação das fotos em grupos de cerca de 20-40 que correspondam a uma mesma porção de cada ilha; 2) demarcação do contorno das ilhas em cada foto através de máscaras para ocultar áreas de não interesse (céu e mar) a fim de não causar interferências no alinhamento das fotos devido à presença de feições móveis (marolas, por exemplo); 3) alinhamento inicial das fotos de cada grupo; 4) geração da nuvem densa de pontos preliminar para cada grupo; 5) geração da malha poligonal preliminar para cada grupo; 6) geração da textura preliminar de cada grupo; 7) definição de pontos de referência dispostos sobre feições equivalentes que aparecem em grupos distintos para poder alinha-los; 8) alinhamento e fusão dos grupos; 9) refinamento do alinhamento das fotos no grupo fusionado; 10) geração da nuvem de pontos densa final; 11) geração da malha poligonal final; 12) geração da textura final (Figura 3).

A separação de fotos em grupos (etapa 1) foi feita em virtude da dificuldade do programa para, em certos casos, processar e alinhar todas as fotos como um conjunto único (limitação imposta pela quantidade de memória RAM do computador utilizado). Assim, foram separados conjuntos menores, com fotos que cobrem seções distintas de cada ilha. As etapas de alinhamento de fotos (3) e de geração de nuvens densas de pontos (4 e 10), devido ao elevado número de fotos e à grande quantidade de cálculos que o programa precisa fazer, exigem um computador de alto desempenho, tipo Workstation, com processador Intel i7, com grande quantidade de memória RAM (idealmente 
mais de $32 \mathrm{~GB}$ ), placa gráfica independente e disco rígido de estado sólido para melhorar o desempenho de acesso aos dados brutos a modelar, a fim de minimizar o tempo de processamento. Foi utilizado um computador equipado com 12 GB de memória RAM, processador i7 de $3.6 \mathrm{GHz}$ e placa gráfica dedicada de $4 \mathrm{~GB}$, o qual não foi capaz de gerar a nuvem densa final usando o nível de qualidade "ultra-alto", de forma que os modelos foram gerados usando o nível "alto". Mesmo assim, o tempo de processamento da etapa 10 foi de mais de 72 horas para quase todos os modelos.

Figura 3 - Capturas de tela do AgisoftPhotoscan. A) MDE estereofotogramétrico da ilha Redonda e filhote com a localização e orientação das câmeras (em azul) calculadas a partir de um conjunto de fotografias (algumas delas representadas na base da imagem). Câmeras adicionais, de vista aérea, não estão mostradas. B) Detalhe do MDE estereofotogramétrico do Filhote da Cagarras, sem o mapa de textura, para ilustrar o nível de detalhamento de superfície $3 \mathrm{D}$.

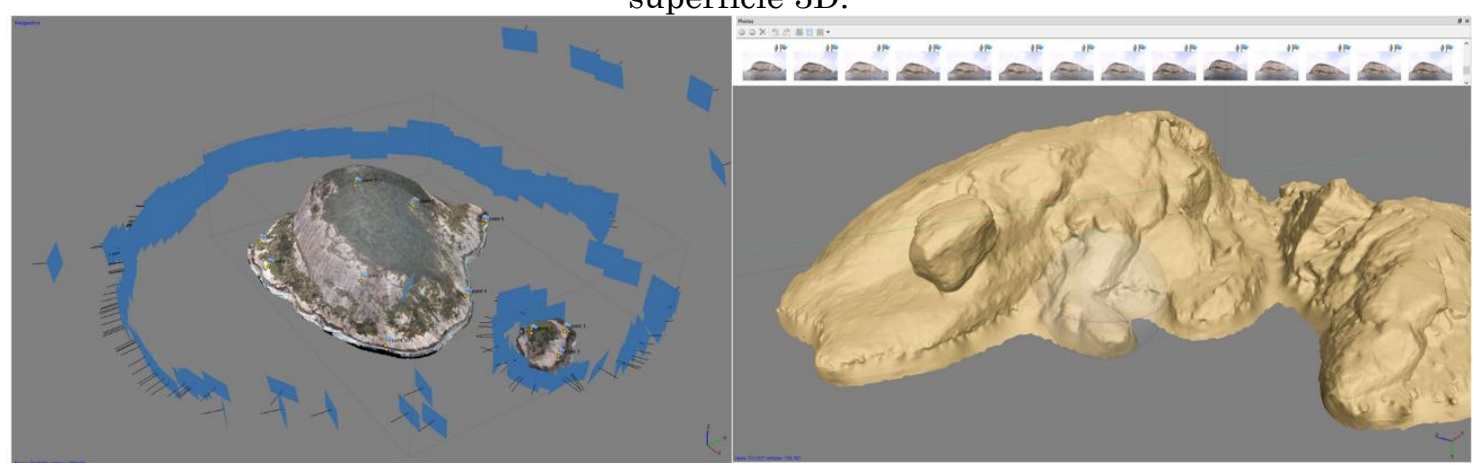

Fonte: Elaborada pelos autores.

2.2.3 Fusão de batimetria e topografia

Os modelos SRTM 30 m e ASTER GDEM foram tratados inicialmente com a ferramenta Reclassify, onde os valores negativos do modelo topográfico foram reclassificados como zero. Nesta mesma ferramenta, os valores positivos do modelo batimétrico foram também reclassificados como zero. Assim, eliminando os dados referentes sobreposições e as extrapolações geográficas do interpolador. No caso da sobreposição, evitou-se que uma célula tivesse simultaneamente dados de topografia e batimetria, ou seja, não foram feitas médias e sim o valor foi arbitrado em função do pixel estar acima ou abaixo do vetor de nível zero. No segundo caso, evitou-se que valores 
fossem interpolados muito distantes dos locais onde haviam medidas amostradas.

Ambos os modelos topográficos foram unidos, individualmente, ao modelo batimétrico utilizando a ferramenta RasterCalculator e nela inserida a expressão de soma de rasters tendo dois MDE como resultado do cálculo matricial. Isso é facilmente implementado uma vez que tanto o MDE topográfico e o batimétrico o mesmo tamanho de célula, estabelecido em 10 $\mathrm{m}$.

Os modelos topográficos estereofotogramétricos, por não terem sido gerados a partir de fotografias georreferenciadas, tiveram de ser escalonados e posicionados utilizando-se os modelos batimétricos como referência. Para tanto, os modelos foram exportados do Photoscan no formato .obj e importados no software Autodesk ${ }^{\circledR}$ 3ds Max 2014. Os dados batimétricos foram exportados do ArcGIS 10 no formato .dxf e importados no 3ds Max, no qual serviu de base para escalonar e posicionar os modelos estereofotogramétricos de cada ilha.

\section{Resultados e discussões}

O modelo batimétrico final é apresentado sobre o relevo sombreado na Figura 4. Interpretando não somente a batimetria como outros aspectos como declividade e curvatura, é possível observar vários aspectos importantes da morfologia das ilhas que compõem o MoNa. A Figura 4A destaca uma grande região central menos profunda entre as ilhas do arquipélago.

Nesse local encontra-se um banco arenoso de acúmulo favorecido pela proteção exercida pela ilha Comprida no que se refere a ondas, correntes e marés. As ondas de SW, que apresentam maior energia, deixam o seu registro entre a ponta oeste da ilha Comprida e a laje da ilha de Palmas, escavando parte do assoalho marinho de SW-NE. Na ponta oeste da ilha Cagarras se inicia um canal com $30 \mathrm{~m}$ de profundidade em média e que se estende até a ponta norte. Outros dois canais menos expressivos são encontrados: um entre 
as ilhas Cagarras e filhote e outro entre a ilha Redonda e filhote (figuras 4A e 4B). Em campo foi possível observar a aceleração da corrente marítima nestes canais, inclusive dificultando a navegação.

Figura 4 - Modelo batimétrico utilizando interpolador Topo to Raster visualizado sobre o relevo sombreado com fonte de iluminação em 315/45.A) Conjunto de ilhas a norte do arquipélago, ilustrando as ilhas de Palmas (1), Cagarra (2), Filhote da Cagarra (3) e

Comprida (4), assim como principais feições da geomorfologia do fundo marinho: banco arenoso entre as ilhas (5), feição erosiva na ponta da ilha Cagarra (6). B) As ilhas Redonda (7) e Filhote da Redonda (8), a sul do arquipélago, com destaque às principais feições da geomorfologia do fundo marinho.

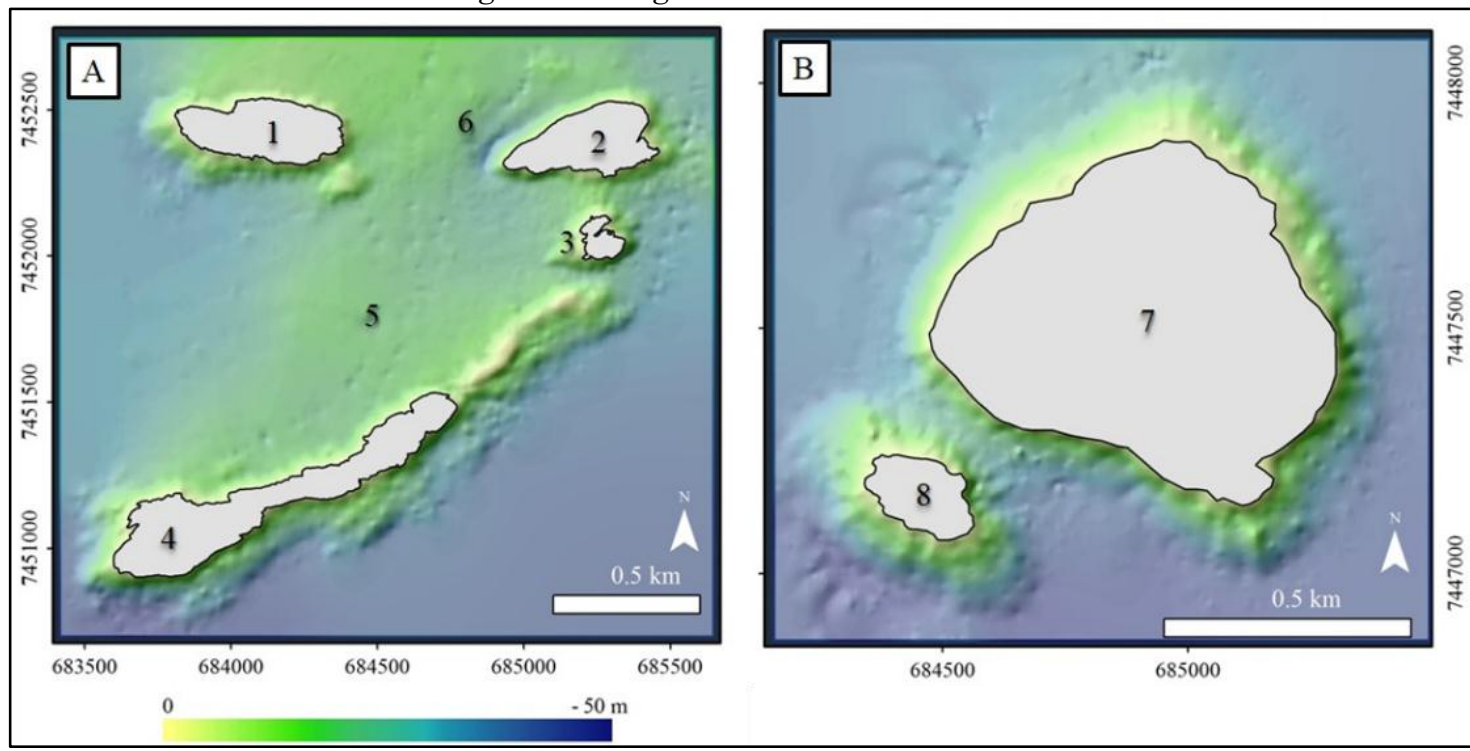

Fonte: Elaborada pelos autores.

Em relação às declividades (Figura 5) e aos tipos de relevo propõem-se três regiões onde as zonas de alta declividade (maior que $40^{\circ}$ ) estão associadas aos costões rochosos escarpados, as zonas de média declividade (entre $20^{\circ} \mathrm{e}$ $40^{\circ}$ ) aos blocos rochosos erodidos e depositados na base do costão e as zonas de baixa declividade (menor que $20^{\circ}$ ) ao assoalho marinho de composição arenosa. 
Figura 5 - Declividades de batimetria e altimetria (ASTER GDEM) fusionadas sobre o relevo sombreado com fonte de iluminação em 315/45. Notar continuidade entre os MDE fundidos e as declividades acentuadas nos lados S e L. Divisão em A) e B) como na figura anterior. Notar a demarcação do ponto culminante de cada ilha (discutidos na Figura 7) e pontos de controle usados na aferição da topografia da Ilha Comprida (discutidos na Figura

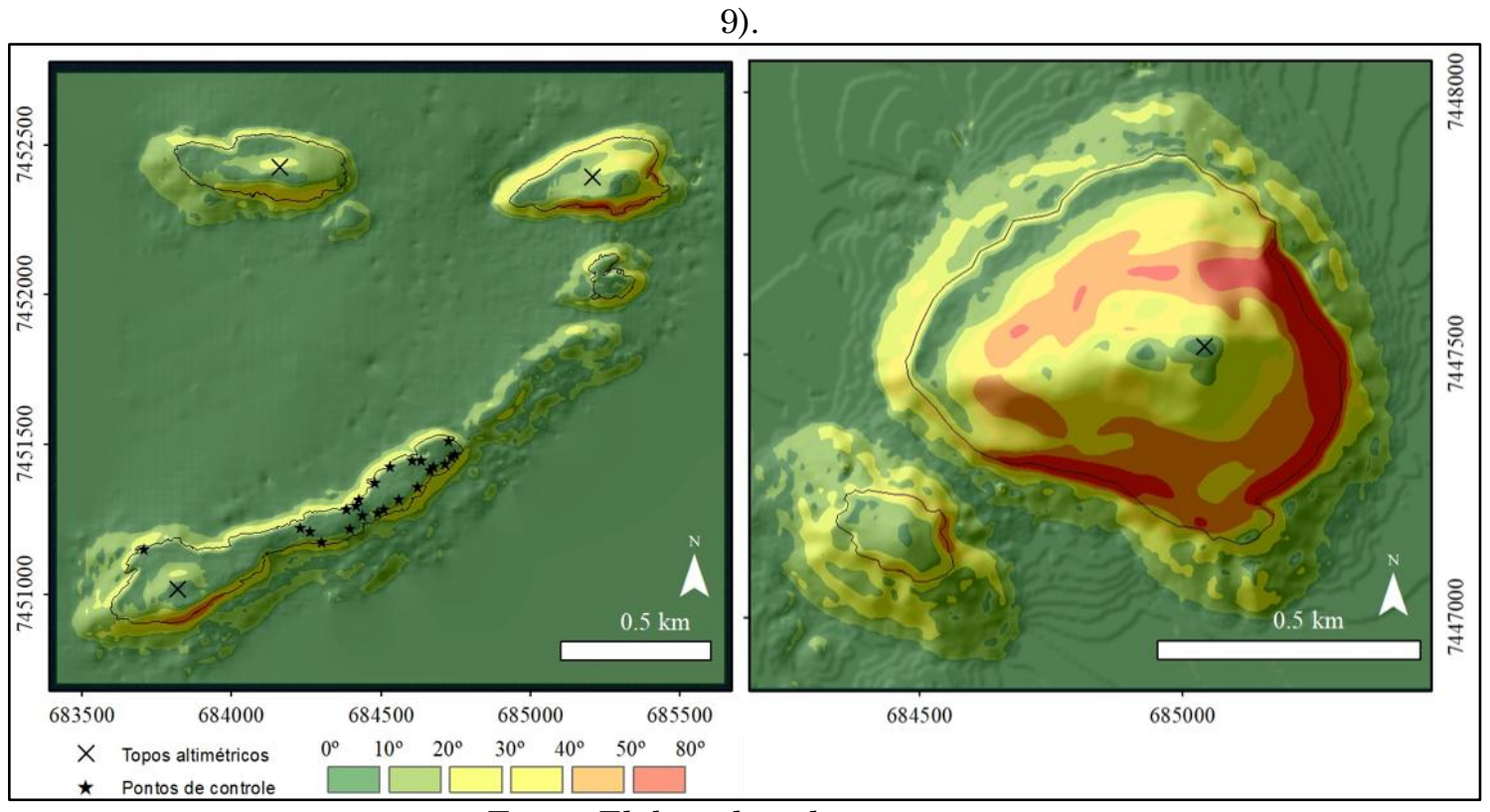

Fonte: Elaborada pelos autores.

O levantamento batimétrico registrou, no total, 20.634 pontos com profundidade média de 20,1 m, máxima de 49,7 m e mínima de 1,9 m. A frequência da distribuição dos valores residuais comparando as medidas registradas com o modelo batimétrico interpolado está apresentada na Figura 6. Nela, observam-se diferenças entre $12 \mathrm{~m}$ e - 6,5 m. No entanto, $95 \%$ dos pontos estão com erros entre $-2,5 \mathrm{~m}$ e $2,8 \mathrm{~m}$.

A média de 0,15 , o desvio padrão de 1,35 e o erro médio quadrático de 0,98, corroboram a escolha do método de interpolação Topo to Raster. Essas medidas estão em metros devido a utilização de sistema de referência UTM, e estes erros são portanto compatíveis com o propósito do trabalho.

Os modelos topográficos SRTM $30 \mathrm{~m}$, ASTER GDEM e o estereofotogramétrico foram analisados em três perspectivas: uma comparando as altitudes máximas de cada modelo por ilha e dados oficiais anteriores, outra a partir de pontos cotados extraídos de GPS com altitudes elipsoidais e por fim, uma comparação visual com a batimetria implementada. 
Figura 6 - Distribuição de frequência do valor residual entre o modelo e o levantamento batimétricos. Notar que os intervalos de confiança obtidos (à direita) se enquadram na Classe $1 \mathrm{~B}$ com até $5 \mathrm{~m}$ de erro para $95 \%$ dos pontos medidos (IHO, 2008).

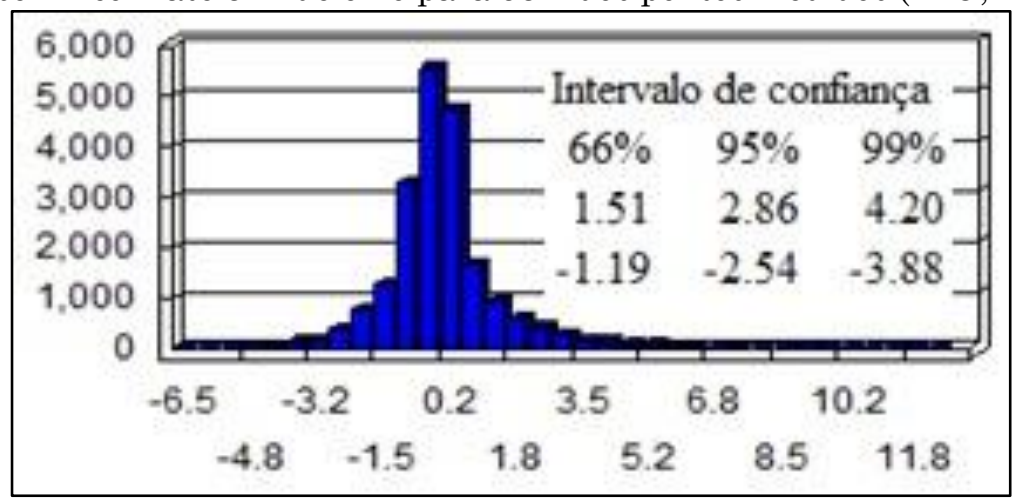

Fonte: Elaborada pelos autores.

Os valores máximos altimétricos indicados por cada um dos modelos foram tabelados juntamente aos dados oriundos da carta topográfica Baía de Guanabara do Instituto Brasileiro de Geografia e Estatística - IBGE, do mapa cadastral 311A do Instituto Pereira Passos - IPP, da carta náutica 1501 folha Baía de Guanabara da Marinha do Brasil e do MDE SRTM com resolução de $90 \mathrm{~m}$.

O ASTER GDEM possui os menores valores obtidos, o modelo estereofotogramétrico tem os maiores valores e o SRTM $30 \mathrm{~m}$ valores entre ambos. As altitudes do SRTM $90 \mathrm{~m}$ se comportam de forma similar ao ASTER GDEM. As cartas topográfica e náutica, além dos dados IPP estão inseridos quase que totalmente dentro deste intervalo, como pode ser observado na Figura 7. As maiores amplitudes, entre os extremos altimétricos, se encontram principalmente nas ilhas Comprida e Palmas. Os altos valores altimétricos do modelo estereofotogramétrico são devido à assimilação da amplitude vertical da vegetação, difícil de ser descontado no caso das ilhas Palmas, Comprida e Redonda. 
Figura 7 - Comparação dos máximos altimétricos de cada ilha nas diversas fontes de consulta (ver Figura 5).

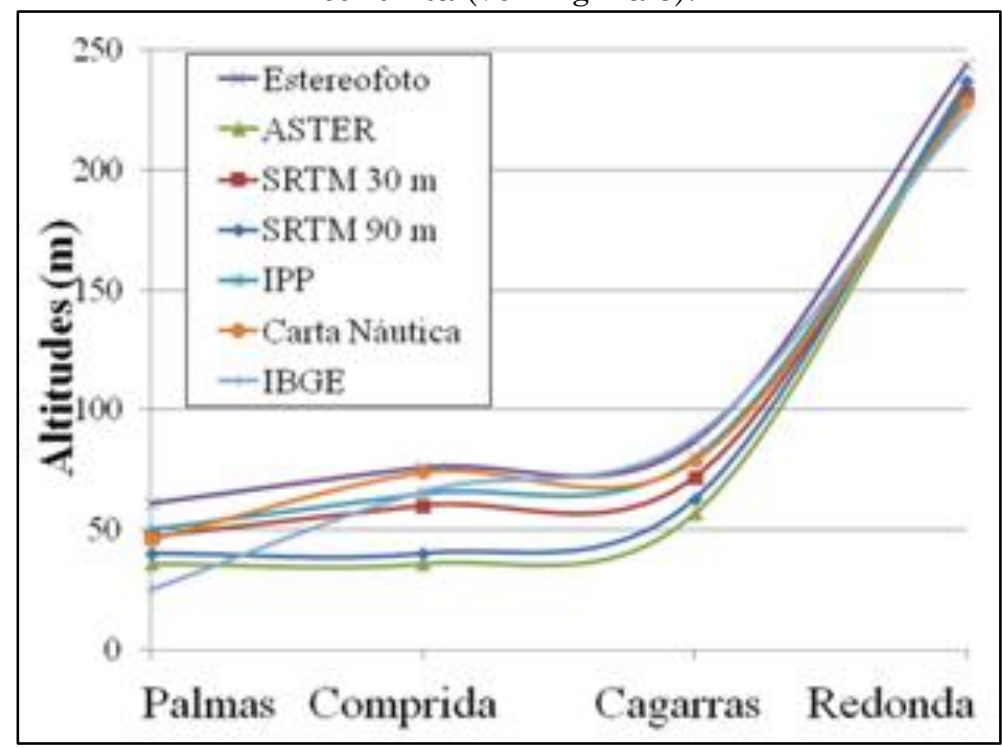

Fonte: Elaborada pelos autores.

Pontos de controle (n=23, Figura 5) foram utilizados para verificação das altitudes de cada um dos modelos e exemplificados na Figura 8. O modelo estereofotogramétrico se mostrou o mais sensível às variações do relevo. Novamente. percebe-se notável suavização dos modelos topográficos orbitais devido a resolução espacial dos produtos de SR.

Figura 8 - Altitudes nos pontos de controle (ver Figura 5) em ordem crescente de altitude a partir do modelo estereofotogramétrico.

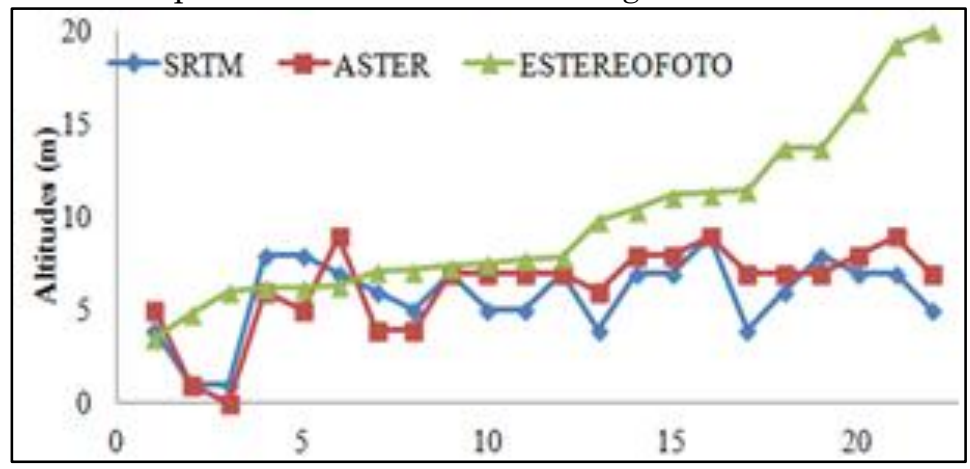

Fonte: Elaborada pelos autores.

Os três modelos foram gerados para toda a área de estudo, mas para comparação visual selecionou-se a região da ilha Redonda e filhote por apresentar a maior amplitude topográfica (Figura 9). O modelo 
estereofotogramétrico capta as nuances do relevo (Figura 9A), aproximandose mais da realidade que o SRTM $30 \mathrm{~m}$ e o ASTER GDEM. O modelo ASTER GDEM é o menos rugoso enquanto o modelo SRTM 30 m apresenta os costões rochosos com declividades mais acentuadas. Ambos os modelos orbitais subestimaram a altitude e a forma sinuosa da Filhote da Redonda. As reentrâncias no costão rochoso, observadas em campo, são mais bem apresentadas pelo modelo estereofotogramétrico.

Figura 9 - Captura de tela dos MDE: A) Estereofotogramétrico com melhor desempenho em assimilar os detalhes do relevo; B) ASTER GDEM modelo mais suavizado dentre todos e C) SRTM $30 \mathrm{~m}$, modelo mais rugoso e que assimilou bem as altas declividades.

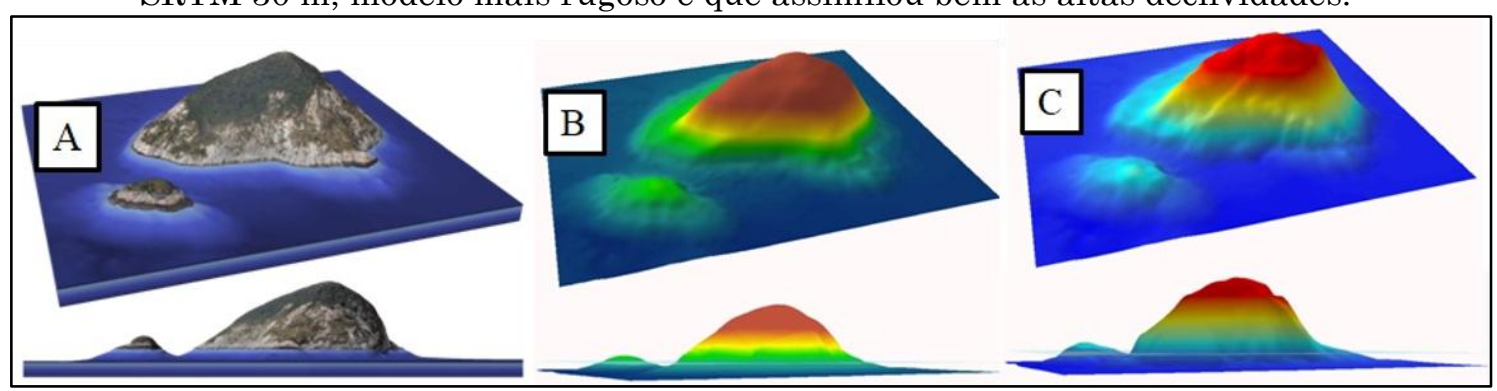

Fonte: Elaborada pelos autores.

\section{Conclusão}

O MDE Estereofotogramétrico se mostrou o melhor entre os discutidos aqui. O interpolador Topo to Raster com erro médio quadrático em $0,98 \mathrm{~m}$ contempla as expectativas do trabalho. A associação de topografia e batimetria mostrou ser possível a união de duas metodologias distintas de aquisição de dados por SR. Tanto o ecobatímetro comercial GPSMap 521s da Garmin ( $R \$ 2.599$ ) quanto o equipamento fotográfico (câmera e lente, aproximadamente $R \$ 2.500$ ) se configuram em equipamentos de baixo custo. Caso fosse contratado um serviço profissional a preços praticados no mercado, o custo para aquisição das imagens aéreas ( $R$ \$ 3.000) seria de uma ordem de grandeza superior (mais de $\mathrm{R} \$ 30.000$ ). Este é portanto, um valor considerado baixo em relação à qualidade dos dados obtidos. 
Neste estudo foi utilizada embarcação de aluguel ( $\mathrm{R}$ \$ 300/dia) em seis campanhas totalizando cerca de $\mathrm{R} \$ 2.000$. Embora não haja necessidade de equipamento fotográfico profissional para geração dos modelos estereofotogramétricos, este é recomendado podendo inclusive ser alugado. A modelagem exige um computador de alto desempenho, especialmente quanto à quantidade de memória RAM (recomenda-se no mínimo $32 \mathrm{~GB}$, mas idealmente $64 \mathrm{~GB}$ ou mais) e este é o item de maior custo com valor em torno de $R \$ 4.000$.

Os procedimentos de planejamento, aquisição, processamento e apresentação de dados, não possuem grande complexidade. São procedimentos que podem ser multiplicados por pares em workshops, aulas presenciais ou não, ou material de consulta por um de nossos órgãos responsáveis pela gestão de áreas protegidas. Dessa forma, este estudo sugere aplicação ampla da metodologia em áreas de proteção marinha em sintonia às indicações do Ministério do Meio Ambiente - MMA - de incentivo à pesquisa em UC, em especial, no levantamento de dados primários. O Monumento Natural das Ilhas Cagarras possui porções emersas e submersas. Áreas de proteção marinha são, em sua maioria, regiões submersas, com pequena ou nenhuma parte emersa. Dessa maneira, o modelo topográfico tem peso menor na avaliação do rigor em relação ao modelo batimétrico.

Este trabalho, junto a outros do grupo de pesquisa, foi apresentado ao Conselho Consultivo do MoNa Cagarras em reunião de discussão do plano de manejo e entregue em formato de Sistema de Informação Geográfica - SIG. O MDE resultante do trabalho serviu de base para a construção de uma maquete, através de impressão 3D. O Projeto Ilhas do Rio, realizado pelo Instituto Mar Adentro, a utiliza em exposições, feiras e palestras para fins educacionais e de representação do monumento natural. Por fim, o SIG se constituirá em uma ferramenta estratégica para a elaboração do primeiro plano de manejo da UC. 


\section{Agradecimentos}

Ao Projeto Ilhas do Rio, coordenando pelo Instituto Mar Adentro, com patrocínio do Programa Petrobrás Ambiental e à CAPES por fomentar essa pesquisa por meio de bolsa de mestrado a JCA. Ao Núcleo de Experimentação Tridimensional da Pontifícia Universidade Católica do Rio de Janeiro (NEXT, PUC/RJ) por permitir o uso do software AgisoftPhotoscan ${ }^{\circledR}$ em seu laboratório. Ao Tata Lacale da DigitalGlobe por cessão da imagem de satélite de alta resolução GeoEye-1. Aos revisores Arthur Ayres Neto e João Wagner de Alencar Castro e aos editores Alan José Salomão Graça e João Vitor Meza Bravo pelas inúmeras contribuições na melhoria do manuscrito.

\section{Referências}

ABRAMS, M. e HOOK, S. ASTER User Handbook: Advanced Spaceborne Thermal Emission and Reflection Radiometer. USA: NASA / Jet Propulsion Laboratory / California Institute of Technology, vol. 2, 2002. 135p.

ARAUJO, J. C.; FORTES, I. S. F. C.; DUARTE, F. C.; PEREIRA, B. S. B. O.; SANTOS, E. E. S.; SEOANE, J. C. S. Low-cost Bathymetric Survey for Marine Protected Areas: coral reefs and coastal islands. IEEE/OES Acoustics in Underwater Geosciences Symposium (Rio Acoustics). 2015. DOI10.1109/RIOAcoustics.2015.7473610. Disponível em $<$ http://ieeexplore.ieee.org/document/7473610/?section=abstract $>$. Acesso em: 20 de dezembro de 2017.

ASTER - ADVANCED SPACEBORNE THERMAL AND REFLECTION RADIOMETER. Disponível em: <http://asterweb.jpl.nasa.gov/>. Acesso em: 27 de Abril de 2017.

BIAS, E. S; BRITES, R. S.; ROSA, A. N. C. S. Imagens de Alta Resolução Espacial. In: Paulo Roberto Meneses; Tati Almeida. (Org.). Introdução ao Processamento de Imagens de Sensoriamento Remoto. $1^{\text {a }}$ edição. Brasilia: CNPq, vol. 1, 2012. pp. 242-267 
BIAS, E. S.; COSTA, R. R. J.; BAPTISTA, G. M. M.; BERNARDI, J. V. E. Avaliação da Precisão do MDE Obtido por Meio do SRTM E pela Carta do IBGE na Escala 1:100.000. Revista Brasileira de Cartografia, vol. 63, 2011. pp. 149-155

BIJU-DUVAL, B.; LE QUELLEC, P.; MASCLE, A.; RENARD, V.; VALERY, P. Multibeam Bathymetric Survey and High Resolution Seismic Investigations on the Barbados Ridge Complex (Eastern Caribbean): a Key to the Knowledge and Interpretation of an Accretionary Wedge. Tectonophysics, vol. 86, n. 1, 1982. pp. 275-304.

COELHO FILHO, L. C. T.; BRITO, J. L. N. S. Fotogrametria Digital, Eduerj, Rio de Janeiro, 2007. 151p.

CWIK, M. R.; MELO, A. C.; CEZAR, G. S.; PELLIZZARI, P. O. Integração de Dados Geofísicos e Geológicos em Projetos de Dutos Rígidos Submersos: Análise dos Métodos de Inferência Espacial. Anais do III Simpósio Brasileiro de Ciências Geodésicas e Tecnologias da Geoinformação. Recife, julho de 2010. pp. $1-6$

DHN. Carta Náutica 1501. Bahia de Guanabara. Disponível em $<$ https://www.marinha.mil.br/chm/chm/dados-do-segnav-cartas-raster/baiade-guanabara>. Acesso em: 20 de Fevereiro 2017

DIAS, L. F. L.; CASTRO, J. W. A.; SEOANE, J. C. S. Pleistocene - Holocene Transition in Anjos Cove, Arraial do Cabo / Rio de Janeiro State: Paleoenvironmental Reconstruction in 3D. Revista Brasileira de Cartografia, vol. 66, 2014. pp. 931-951

FERNANDES, M.; AVELAR, A.; MENEZES, P. M. L.; NETTO, A. L. C. Comparação do Uso de Superfície Real e Planimétrica para Análises do Índice de Eficiência de Drenagem: um Estudo de Caso no Maciço da Tijuca - RJ. Revista Brasileira de Geomorfologia, vol. 13, n. 1, 2012. pp. 29-37

FLORENZANO, T. G. Iniciação em Sensoriamento Remoto. Oficina de Textos, 2007. 123p.

FUCKNER, M. A., FLORENZANO, T. G., E MORAES, E. C. Avaliação Altimétrica de Modelos Digitais de Elevação Extraídos de Imagens ASTER em Áreas com Configuração Topográfica Distinta. Anais do XIV Simpósio Brasileiro de Sensoriamento Remoto, Natal, Brasil, 2009. pp. 25-30 
GAO, J. Bathymetric Mapping by Means of Remote Sensing: Methods, Accuracy and Limitations. Progress in Physical Geography, vol. 33, n. 1, 2009. pp. 103116

HATANAKA, K., TODA, M., WADA, M. Data Analysis of a Low-cost Bathymetry System Using Fishing Echo Sounders. Oceans Conference Record (IEEE). OCEANS 2007 MTS/IEEE Conference, Vancouver, BC, 2007. DOI: 10.1109/OCEANS.2007.4449181.

Disponível

em $<$ https://ieeexplore.ieee.org/document/4449181/>. Acesso em: 20 de dezembro de 2017.

HEEZEN, B. C.; THARP M.; EWING M. The Floors of the Oceans: I. The North Atlantic. Geological Society of America, .vol.65, 1959. 122p.

HEYMAN, W.D.; ECOCHARD, J.-L. B.; BIASI, F. B; Low-cost Bathymetric Mapping for Tropical Marine Conservation - A Focus on Reef Fish Spawning Aggregation Sites. Marine Geodesy, vol. 30, 2007. pp. 37-50

HORTA, J.; PACHECO, A.; MOURA, D.; FERREIRA, O. Can Recreational Echosounder-Chartplotter Systems be used to Perform Accurate Nearshore Bathymetric Surveys? Ocean Dynamics, vol. 64, n. 11, 2014. pp. 1555-1567

HUTCHINSON, M. F. Calculation of Hydrologically Sound Digital Elevation Models. Proceedings of the Third International Symposium on Spatial Data Handling at Sydney, Australia, 1988. pp. 117-133,

HUTCHINSON, M. F. A New Procedure for Gridding Elevation and Stream Line Data with Automatic Removal of Spurious Pits. Journal of Hydrology, vol. 106, 1989. pp. 211-232

INTERNATIONAL HYDROGRAPHIC ORGANIZATION. Depth Determination.

(Chapter 3). Manual on Hydrography. International Hydrographic Bureau, Monaco, 2002. pp. 119-197

INTERNATIONAL HYDROGRAPHIC ORGANIZATION IHO Standards for Hydrographic Surveys. $5^{\text {th }}$ Edition. Technical Report 44. International Hydrographic Bureau, Monaco, 2008. 28p.

JENSEN, J. R. Sensoriamento Remoto do Ambiente: uma perspectiva em recursos terrestres (tradução da segunda edição). São José Dos Campos, Parêntese Editora, 2009. 598p., 
JPL Jet Propulsion Laboratory, NASA (National Aeronautics and Space Administration). U.S. Releases Enhanced Shuttle Land Elevation Data. Disponível em <http://www2.jpl.nasa.gov/srtm/>. Acesso em 30 de agosto de 2017.

KRUG, L. A.; NOERNBERG, M. A. Extração de Batimetria por Sensoriamento Remoto de Áreas Rasas dos Sistemas Estuarinos do Estado do Paraná - Brasil. Anais do Simpósio Brasileiro de Sensoriamento Remoto, vol. 12, 2005. pp. 3077-3084

KVERNEVIK, T.-I.; AKHIR, M. Z. M.; STUDHOLME, J. A Low-Cost Procedure for Automatic Seafloor Mapping, with Particular Reference to Coral Reef Conservation in Developing Nations. Hydrobiologia, vol. 474, n. 1-3, 2002. pp. 67-79

MALLISON, H.; WINGS, O. Photogrammetry in Paleontology - a Practical Guide. Journal of Paleontological Techniques, vol. 12, 2014. pp. 1-31

MICELI, B. S.; DIAS, F. M.; SEABRA, F. M.; SANTOS, P. R. A.; FERNANDES, M. C. Avaliação Vertical de Modelos Digitais de Elevação (MDES) em Diferentes Configurações Topográficas para Médias e Pequenas Escalas. Revista Brasileira de Cartografia, vol. 63, 2011. pp. 1-10

MIRANDA, E. E. (COORD.) Brasil em Relevo. Campinas: Embrapa Monitoramento por Satélite, 2005. Disponível em: <http://www.relevobr.cnpm.embrapa.br>. Acesso em: 20 de Fevereiro de2018.

MELGAÇO, L. M.; SOUZA FILHO, C. R.; STEINMAYER, M. Comparação entre Modelos Digitais de Elevação Gerados por Sensores Ópticos e por Radar. Anais do Simpósio Brasileiro de Sensoriamento Remoto, v. 12, p. 1215-1220, 2005 .

MORAES, E. C. Fundamentos de Sensoriamento Remoto (Capítulo 1). Apostila de Sensoriamento Remoto - INPE. São José dos Campos: INPE, 2002. pp. 1-22

POULIQUEN, E.; LURTON, X. Identification de La Nature du Fondde la Meral'aidede Signaux D'écho-Sondeurs. Le Journal de Physique IV, vol. 2, n. C1, 1992. pp. C1-941-C1-944 
PICKRILL, R. A., TODD, B. J. The multiple roles of acoustic mapping in integrated ocean management, Canadian Atlantic continental margin. Ocean e Coastal Management, vol.46, 2003. pp. 601-614

SÁNCHEZ-CARNERO, N.; ACEÑA, S.; RODRÍGUEZ-PÉREZ, D.; COUÑAGO, E.; FRAILE, P.; FREIRE, J. Fast and Low-Cost Method for VBES Bathymetry Generation in Coastal Areas. Estuarine, Coastal and Shelf Science, vol. 114, 2012. pp. 175-182

TACHIKAWA, T.; HATO, M.; KAKU, M.; IWASAKI, A. The Characteristics of ASTER GDEM Version 2, Geoscience and Remote Sensing Symposium (IGARSS), 2011. DOI10.1109/IGARSS.2011.6050017. Disponível em $<$ https://ieeexplore.ieee.org/document/6050017/>. Acesso em: 20 de dezembro de 2017.

TIGHE, M. L.; CHAMBERLAIN, D. Accuracy Comparison of the SRTM, ASTER, NED, Nextmap ${ }^{\circledR}$ USA Digital Terrain Model over Several USA Study Sites. In: Proceedings of the Asprs/Mapps 2009 Fall Conference, San Antonio, TX. 2009. Disponível em <https://www.asprs.org/wpcontent/uploads/2010/12/Tighe_2.pdf/>. Acesso em: 20 de dezembro de 2017.

TOMMASELLI, A. M. G. Fotogrametria Básica. Notas de Aula de Fotogrametria Curso de Graduação em Engenharia Cartográfica - FCT/UNESP. Presidente Prudente, 79 p., 2009.

TOMAZONI, J. C.; GUIMARÃES E.; GOMES, T. C.; SILVA, T. G. D. A. Uso de Modelo Digital de Elevação gerados a partir do ASTER GDEM e SRTM para caracterização de rede de drenagem. Revista Brasileira de Geografia Física. n.2., 2011. pp.365-376

VALERIANO, M. DE M.; ROSSETTI, D. F. Topodata: Seleção de Coeficientes Geoestatísticos para Refinamento Unificado de Dados SRTM. INPE16701-RPQ/853. São José dos Campos: INPE, 74p. 2010. Disponível em $<$ http://mtc-m16d.sid.inpe.br/col/sid.inpe.br/mtcm19@80/2010/05.10.18.35/doc/publicacao.pdf/>. Acesso em: 20 de dezembro de 2017.

VICENTE, J.; ARTILHEIRO, F.; PEIRIÇO, A. A Primeira História dos Sondadores Multifeixe do IH. Anais do Instituto Hidrográfico, n. 17, 2005. pp. 13-32 
VILMING, S. The Development of the Multibeam Echosounder: an Historical Account. The Journal of the Acoustical Society of America. vol. 103, 1998. pp. 29-35 